\title{
Endovascular Treatment of Ruptured Dissecting Basilar Artery Aneurysm: One Case Report
}

\author{
Woo Mok Byun, Bok Hwan Park \\ Departments of Diagnostic Radiology, \\ College of Medicine, Yeungnam University, Daegu, Korea.
}

-Abstract-

Optimal treatment for ruptured dissecting basilar artery aneurysms in patients presenting with $\mathrm{SAH}$ is endovascular method using stent placement and coil embolization. We report a case (52-year-old woman) of ruptured dissecting aneurysm of the basilar artery which was treated with stent placement and coil embolization.

Key Words: Endovascular treatment, Ruptured dissecting basilar artery aneurysm

Introduction

Dissecting basilar artery aneurysms in patients presenting with subarachnoid hemorrhage (SAH) are life threatening, especially in those who experience subsequent bleeding or progressive dissection, and immediate treatment may be necessary. ${ }^{1)}$ The optimal treatment of a ruptured dissecting aneurysm is to prevent subsequent rupture with preservation of patency of the basilar artery. Although there are several reports about treatment methods, management is still controversial and difficult. ${ }^{2-5)}$ With improvement in stents, their increased use in the treatment of dissecting aneurysm has become apparent. ${ }^{6-8)}$

We report a case of ruptured dissecting aneurysm of the basilar artery which was treated with stent placement and coil embolization.

\section{Case report}

52-year-old woman presented with sudden dizziness, nausea and vomiting. Computed tomography exhibited diffuse SAH, predominately within the pre- ${ }^{-}$and lateral medullary cisterns (Fig. 1-A). Cerebral angiography 
- Endovascular Treatment of Ruptured Dissecting Basilar Artery Aneurysm: One Case Report -
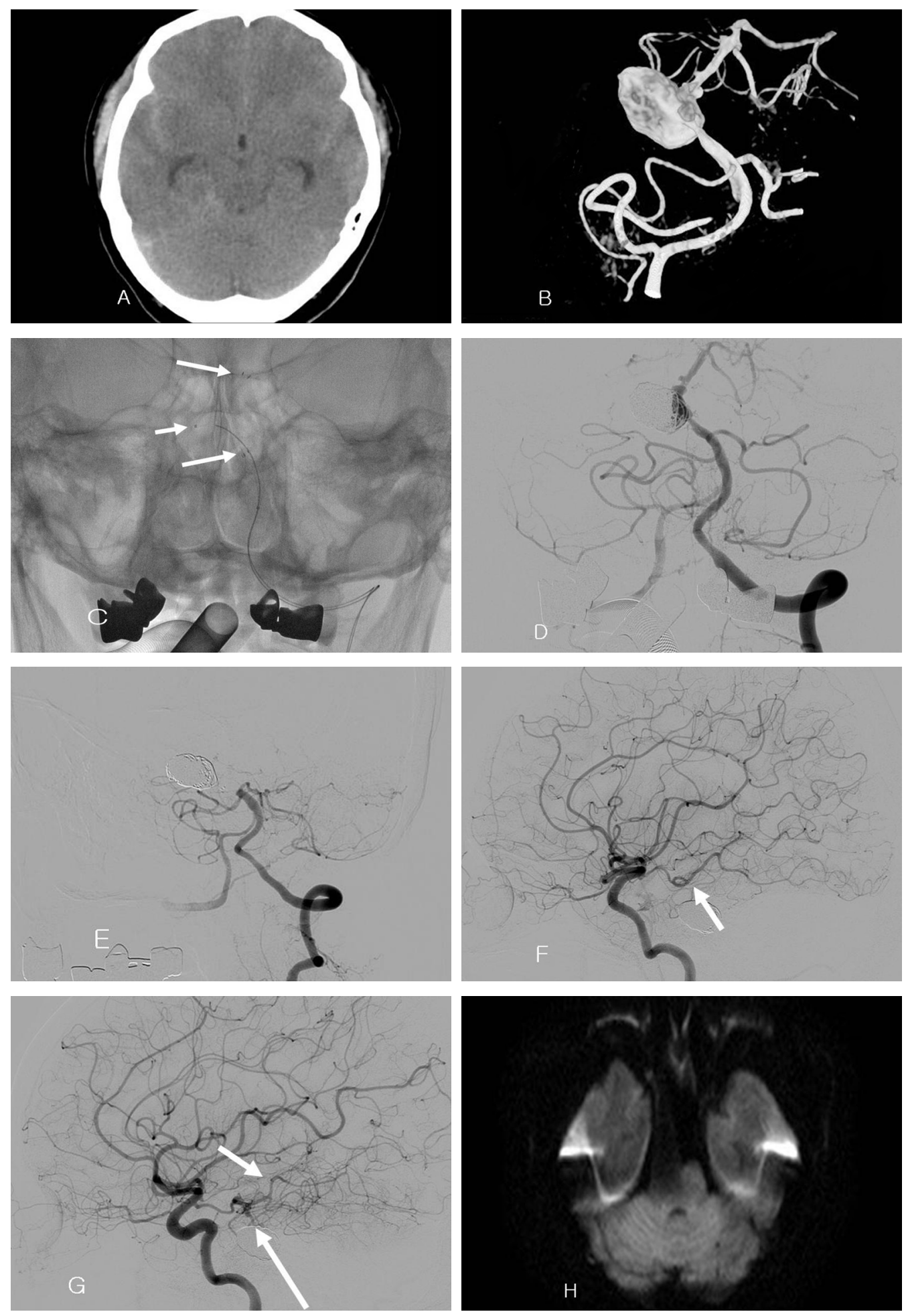
- Woo Mok Byun · Bok Hwan Park -

Fig. 1. Ruptured dissecting aneurysm of the basilar artery performed endovascular treatment.

Noncontrast CT (A) shows diffuse SAH, predominately within the pre- and lateral medullary cisterns. A $16 \times 12 \mathrm{~mm}$ sized aneurysm with irregular margin in the middle part of basilar artery is noted on 3D angiography (B). Parent basilar artery revealed mutifocal alternating stenosis and dilatation. Fluoroscopy image (C) shows a self expandable stent (large arrows) positioned across the aneurysm and a microcatheter (small arrow) in aneurysm lumen. Catheter angiography (D) after embolization of the aneurysm using eleven detachable coils shows well preserved parent basilar artery and near total occlusion of the aneurysm. A routine follow up angiography (E) performed after seven days showed complete occlusion of aneurismal sac and midportion of basilar artery adjacent to aneurysm. In both internal carotid angiography (F, G), both posterior cerebral and superior cerebellar arteries (small arrows) were preserved through both posterior communicating arteries. Note patent proximal basilar artery (large arrow). Diffusion MR imaging (H) performed on the same day revealed no acute infarction in the pons.

performed on the same day demonstrated 16 $\mathrm{x} 12 \mathrm{~mm}$ sized aneurysm with irregular margin in the middle part of basilar artery. Parent basilar artery revealed mutifocal alternating stenosis and dilatation (Fig.1-B). This aneurysmal dilatation was thought to be a dissecting aneurysm, unsuitable for surgical clipping or standard endovascular coil embolization because of its wide neck. To achieve obliteration of the rupture point of the aneurysm and to preserve the blood flow through the basilar artery, stent assisted coil embolization was performed. A 6 French guiding catheter was placed in the left vertebral artery via a transfemoral approach. A self expandable stent (Neuroform 3 stent $3.5 \mathrm{~mm}$ in diameter $/ 20 \mathrm{~mm}$ in length; Boston Scientific, Freemont, CA) was advanced over the guidewire and positioned across the aneurysm. A microcatheter (Excelsior SL-10, Boston Scientific) was navigated into aneurysm lumen, through the stent struts, via the left vertebral artery, so that eleven detachable coils (Guglielmi detachable coil [Boston Scientific, Natick, MA] and MicroPlex helical coils [Microvention Inc, Aliso Viejo, CA]) could be deployed within the body and dome of the aneurysm (Fig. 1-C).

Angiography after stenting and coil embolization demonstrated occlusion of the body and dome of the aneurysm with excellent blood flow through the basilar artery (Fig. 1-D). After procedure, she showed no focal neurologic deficit. A routine follow up angiography performed after seven days showed complete occlusion of aneurismal sac and midportion of basilar artery adjacent to aneurysm (Fig. 1-E). But both anterior inferior cerebellar arteries were patent without occlusion. Both posterior cerebral and superior cerebellar arteries were preserved through both posterior communicating arteries (Fig. 1-F, G). Although there was parent basilar artery occlusion, diffusion MR imaging performed on the same day revealed no acute infarction in the pons and she showed no neurologic deficits 
(Fig.1-H). She is maintaining a normal life without any neurologic deficits after discharge.

\section{Discussion}

Although intracranial dissecting aneurysm is a variant of the brain aneurysm, its pathogenesis remains obscure. Pathologic studies of dissecting aneurysm with subarachnoid hemorrhage showed that the plane of dissection is between the media and adventitia, with a rupture site in the adventitia. ${ }^{9)}$ Many patients run a severe course and are left with a major neurological deficit or die.

Current approaches to treatment of arterial dissections can be divided into deconstructive and reconstructive. Deconstructive surgical or endovascular techniques included proximal occlusion of the parent artery and trapping of the involved segment. Deconstructive procedures only can be sufficient if branch vessels are not involved in the segment of the vessel to be occluded and collateral blood flow to the remainder of the circulation is adequate. Reconstructive methods preserve the parent vessel, which can be acceptable when angiography reveals inadequate collateral flow or when the dissected segment involves major branch vessels or perforators. Recently endovascular revascularization of the affected artery has involved the use of stent and/or coils as an alternative to surgery. The endovascular methods are much easier and safer than surgical treatment. ${ }^{10)}$
Amin-Hanjani et al. ${ }^{11)}$ reported that follow up results of ten patients (six men and four women; mean age, $40 \mathrm{yr}$ ) with spontaneous dissection of the basilar artery. Clinically, six were admitted with SAH and four were admitted with brain stem ischemia. Nine patients were treated medically, and one underwent selective intravascular occlusion of the dissecting aneurysm. One patient died after further SAH, two remain severely disabled, three have residual neurological deficit, and four are in good clinical condition. They concluded that in light of the possibility of spontaneous healing or improvement, wrapping should be reserved for only those patients with recurrent $\mathrm{SAH}$ or angiographic progression of the dissection. Henkes et al. reported that four cases of endovascular coil occlusion of the basilar artery for the treatment of fusiform dissecting aneurysms was performed.

In our case although successful stenting with coil embolization for the ruptured dissecting aneurysm of the basilar artery is performed, follow up angiography reveals complete occlusion of mid portion of basilar artery including dissecting aneurysm. Antiplatelet therapy after stenting and coil embolization was not performed, because of possibility of rebreeding from embolized aneurysm. But continuous antiplatelet therapy after stenting is very important for patency of the parent artery. Diffusion MR imaging performed on the same day revealed no 
acute infarction in the pons and she showed no neurologic deficit. Follow up angiography of the both internal carotid angiography revealed both posterior communicating arteries connect both internal carotid arteries to both posterior cerebral and distal basilar arteries. This is a route for collateral flow to reach the basilar artery from the carotid artery. We thought to determine whether such collateral flow was beneficial in a setting in which brain stem perforating artery origins were likely to be obstructed by basilar artery occlusion. ${ }^{12)}$ Authors suggest that collaterals for perforators of the basilar artery were developed from superior cerebellar and anterior inferior cerebellar arteries. Fortunately, our patient had no neurologic deficit due to collaterals.

Kang et al. $^{13)}$ reported that successful treatment with neuroform stent placement and coil embolization for ruptured basilar artery dissection was performed. Follow up MR angiography performed six weeks later showed the well reconstructed parent artery and no residual flow within the aneurismal part. They prescribed oral antiplatelet medication including aspirin 300mg and clopidogrel 75mg until six weeks after procedure.

In conclusion, optimal treatment for dissecting basilar artery aneurysms in patients presenting with $\mathrm{SAH}$ is endovascular method using stent placement and coil embolization. Antiplatelet therapy after procedure is very important for patency of the parent artery.

\section{요 약}

뇌지주막하출혈로 발현된 환자의 파열된 기 저동맥박리 동맥류의 합당한 치료는 stent설치 와 코일색전술을 이용한 혈관내 치료법이다. 저자들은 stent설치와 코일색전술로 치료된 파 열된 기저동맥박리 동맥류 52 세 여자 환자의 증례를 보고한다.

\section{References}

1. Kai Y, Hamada J, Morioka M, Yano S, Hamasaki K, Ushio Y. Successful treatment of a ruptured dissecting basilar artery aneurysm. Case report. Journal of neurosurgery 2004;100 (6): $1072-5$

2. Ali MJ, Bendok BR, Tella MN, Chandler JP, Getch CC, Batjer HH. Arterial reconstruction by direct surgical clipping of a basilar artery dissecting aneurysm after failed vertebral artery occlusion: technical case report and literature review. Neurosurgery 2003;52(6):1475-80

3. Choi $\mathrm{CH}$, Cho WH, Choi BK, Lee SW. Rerupture following endovascular treatment for dissecting aneurysm of distal anterior inferior cerebellar artery with parent artery preservation: retreatment by parent artery occlusion with Guglielmi detachable coils. Acta neurochirurgica 2006;148 (3):363-6

4. Fiorella D, Albuquerque FC, Han P, McDougall CG. Preliminary experience using the Neuroform stent for the treatment of cerebral aneurysms. Neurosurgery 2004;54(1):6-16

5. Henkes H, Liebig T, Reinartz J, Miloslavski E, Kirsch M, Kuhne D. Endovascular occlusion 
of the basilar artery for the treatment of dissecting and dysplastic fusiform aneurysms. Der Nervenarzt 2006;77(2):192-200

6. Kaku Y, Yoshimura S, Yamakawa H, Sakai N. Failure of stent-assisted endovascular treatment for ruptured dissecting aneurysms of the basilar artery. Neuroradiology 2003;45 (1):22-6

7. Phatouros CC, Sasaki TY, Higashida RT, et al. Stent-supported coil embolization: the treatment of fusiform and wide-neck aneurysms and pseudoaneurysms. Neurosurgery 2000;47 (1):107-13

8. Willing SJ, Skidmore F, Donaldson J, Nobo UL, Chernukha K. Treatment of acute intracranial vertebrobasilar dissection with angioplasty and stent placement: report of two cases. AJNR 2003;24(5):985-9

9. Kim $\mathrm{CH}$, Son YJ, Paek SH, Han MH, Kim JE, Chung YS, et al. Clinical analysis of vertebrobasilar dissection. Acta neurochirurgica 2006;148(4):395-404

10. Ahn JY, Chung SS, Lee BH, Kim SH, Yoon $\mathrm{PH}$, Joo JY, et al. Treatment of spontaneous arterial dissections with stent placement for preservation of the parent artery. Acta neurochirurgica 2005;147(3):265-73

11. Amin-Hanjani S, Ogilvy CS, Buonanno FS, Choi IS, Metz LN. Treatment of dissecting basilar artery aneurysm by flow reversal. Acta neurochirurgica 1997;139(1):44-51

12. Cross DT, 3rd, Moran CJ, Akins PT, Angtuaco EE, Derdeyn CP, Diringer MN. Collateral circulation and outcome after basilar artery thrombolysis. AJNR 1998;19(8):1557-63

13. Kang SK, Roh HG, Han MH. Rupture basilar artery dissection: successful treatment with neuroform stent palcement and coil embolization. Neurointervention 2007;2(1):65-70. 